УДК 821.161.1.09”20”

\title{
Е.Е. Иванов
}

\section{МЕТАМОТИВ НАСИЛЬСТВЕННОЙ СМЕРТИ В ПРОЗЕ ГАЙТО ГАЗДАНОВА.}

В статье анализируется роль метамотива насильственной смерти в поэтике прозы Газданова («Возвращение Будды», «Призрак Александра Вольфа», «Пленник»). При этом мотив убийства рассматривается в связи с мотивом сна как единый смысловой комплекс, отражающий трансгрессию выхода за рамки наличной реальности. Онейротоп в указанных произведениях не только определяет модусы невозможного (такие, как остранение реальности через наррацию призрака в «Возвращении Будды» или ирреализм в «Призраке Александра Вольфа»), но и передаёт имманентную авторскую стратегию «перерождения». В данной статье интенция газдановского героя к обретению самости впервые описывается в ракурсе идей Гурджиева («человек- спящая машина», «плюралистичность сознания» и др.). Художественные тексты Газданова соотносятся с положениями его учения о нравственном преобразовании личности. С помощью традиционных методов сплошной выборки, мотивного и типологического анализа были выявлены специфические черты метамотива насильственной смерти у Г. Газданова в интертекстуальном освещении. Газдановский герой представлен в антропологической парадигме Ф. Шиллер-А. Пушкин-Ф. Достоевский с одной стороны, с другой, дано определение его места в романтической серии «лишних людей», идущих от Адольфа Константа. Отдельно отмечено предваряющее убийство изменённое состояние сознания в виде борьбы со сном, которое наблюдается во всех текстах и позволяет говорить о метатекстуальности темы убийства в творчестве писателя. Через призму метамотива насильственной смерти предложен новый подход к пониманию доминирующего в художественном мире Г. Газданова дискурса мортальности, который представлен как интенция к «пробуждению». Опыт перехода в контексте призрачности и сноподобия войны и эмиграции тотально остраняет историческую реальность и оценивается как антистановление. Вместе с тем, непоколебимая вера лирического героя в «перерождение» манифестирует витализм, который оказывается парадоксальной изнанкой мортальности.

Ключевье слова: ирреализм, онейротоп, трансгрессия, «спящая машина», мотив убийства.

DOI: $10.35634 / 2412-9534-2020-30-2-311-319$

Проза Г. Газданова благодаря обширному корпусу работ исследована с самых разных позиций. Однако его художественной философии, в основе которой лежит иррационализм, уделено недостаточно внимания. А вместе с тем в его произведениях упоминаются Платон, Юм, Паскаль, Лейбниц, Дюркгейм и др. мыслители. В данной статье элементы поэтики (мотив, наррация и др.) рассматриваются в сочетании с актуальными подходами к понятиям трансгрессии, «возможные миры» и др. Г. Газданов, переживший опыт войны в юном возрасте, с первых шагов в литературе осмыслял потрясение революции, природу насилия и пути предотвращения массовых убийств. Война не отпускает автобиографического героя в первом романе «Вечер у Клэр». Напоминает о прошлом и Вторая мировая война. Реэкзистенция войны не оставляет писателя ни наяву, ни во сне. «Именно во сне опыт осознания себя убийцей наиболее естествен и правдоподобен. К сновидению здесь уже нельзя относиться как к субституту чего-либо, как к чему-либо по преимуществу символическому. К сновидению в данном случае уместно было бы отнестись как к непосредственному опыту» [15, с. 381]. В статье «Заметки об Эдгаре По, Гоголе и Мопассане» Г. Газданов, цитируя Э. По, утверждает «значительность иррационального начала» в искусстве: «Я предлагаю эту книгу вниманию тех, кто поверил в сны, как в единственную реальность» [5, с. 717]. В «Призраке Александра Вольфа» эпиграфом к третьему рассказу: «Приключение в степи» стояла строка из Э. По: «Beneath me lay my corpse with the arrow in my temple» «Подо мною лежит мой труп со стрелой в виске» [6, с. 9]. Эти цитации отражают суть ирреализма самого Г. Газданова - осознание реальности как сна в рецепции и наррации внешнего наблюдателя-призрака и остранение реальной жизни как потустороннего проекта. «Мир состоял для меня из вещей и ощущений, которые я узнавал, так, как если бы я когда-то давным-давно уже испытал их и теперь они возвращались ко мне точно из времени сна» [6, с. 142].

Романы Г. Газданова «Возвращение Будды», «Призрак Александра Вольфа» и рассказ «Пленник» связаны темой посмертного существования героев в призрачно-фантомной форме, которая реализуется в метамотиве насильственной смерти. Событие совершения убийства предваряется либо пуантом борьбы со сном, который предполагает изменённое состояние сознания («Призрак Алек- 
сандра Вольфа» и «Пленник»), либо топикой сна наяву («Возвращение Будды»): «я жил и двигался точно окруженный легким туманом, лишавшим предметы и людей резкой отчетливости контуров... Я засыпал и просыпался с этим ощущением бесформенной тревоги и предчувствия» [6, с. 155]. Автор, размывая спациальные рамки происходящего, создаёт атмосферу неразличения грёзы и яви: «сумерки...проход оказался удивительно длинным... За поворотом было еще темнее ...попадались ниши, назначение которых мне представлялось загадочным» [6, с. 155]. В «Призраке Александра Вольфа» факт убийства фиксируется как постфактум, оставляя поле для интерпретаций. А начинается история неопределённо и неотчётливо: «Я не мог бы точно описать то, что было до этого, потому что все проходило в смутных и неверных очертаниях, характерных почти для всякого боя каждой войны... Я совершенно потерял представление о времени, я не мог бы даже сказать, где именно я тогда находился...я не спал перед этим две с половиной ночи...Мне смертельно хотелось спать, мне казалось тогда, что самое большое счастье, какое только может быть, это остановиться, лечь на выжженную траву и мгновенно заснуть, забыть обо всем решительно. Но именно этого нельзя было делать, и я продолжал идти сквозь горячую и сонную муть, изредка глотая слюну и протирая время от времени воспаленные бессонницей и зноем глаза.» [6, с. 5-6]. Рассказ «Пленник»: «Офицеру снова захотелось спать. Он пересилил себя ... Они сели — и офицер заснул, не успев закрыть рта ...Туман застелил глаза офицеру; ему так хотелось спать, что он едва не дремал стоя» [6, с. 701]. В аллегории сна в «Пленнике» фантомный антогонист недалёкого офицера предрекает, что «сонная болезнь» войны перерастёт в «эпидемию» [6, с. 700] всей России. Мир легимитизированного насилия предстаёт как «сонное царство» [6, с. 702]. Выпадение из реальности - угроза планетарного масштаба: «это в ночной темноте тихо вздрагивает и колеблется огромная тяжесть вращающейся земли?» [6, с. 699]. А само убийство в этой логике «коллективного бреда» говорит о «неподвижности», безвольности, сонной бесконтрольности, как бы призрачном колыхании воинов, тотально обречённых на смерть. Не случайно, по свидетельству Т. А. Бернштам, возвращающегося с войны солдата отправляют к дому в сопровождении «братьев, ведущих его под руки» [4, с. 211] как лишенное витальности существо.

Онейротоп генерализирует поэтику не только этих ирреалистических произведений автора, но и предшествующий им «Вечер у Клэр» с его «сном о Клэр» в сильной позиции конца романа и метафорой «смерть любви» [5, с. 47] в переходе к воспоминаниям-грёзам или, в определении автора, «искусству воспоминаний». «Когда мы говорим о моделировании сновидения, то необходимо помнить, что спящий прежде всего лежит неподвижно с закрытыми глазами, как мертвец или как человек после coitus'a. ... само сновидение является метафорой смерти и метонимией любви» [15, с. 207]. Игра иллюзорного на поверхности, и исчезающего истинного в глубине, напоминающая технику сфумато Леонардо да Винчи, прекращается только во «французском» романе «Пробуждение», в котором признаки фантастического отсутствуют и герой свободен от кошмаров «призрачной неверности судьбы» («Возвращение Будды») [6, с. 154].

Потенциальные модификации сна (наваждение, забытье, провалы в бессознательное) в творчестве раннего Г. Газданова канализируют травматический опыт «гражданской войны» [6, с. 695]. При этом саморефлексия лирического героя представляется «рыбой в неведомом море» [5, с. 46]. Трансгрессия Николая Соседова связана с желанием подвергнуть обманчивый видимый мир риску, пробным опытом чего стала опасная связь с карточными шулерами. Азартная игра и риск быть убитым на войне трансгридиентны. Интеллигент Соседов подвергается самоиспытанию связью с маргинальным миром и опасностью быть убитым ради преодоления контингентности бытия. Его тяготит отсутствие самости и детерминизм внешнего хода событий. С первых произведений газдановский герой-визионер сообщает о протеистичности сознаний в своём внутреннем мире и несогласованности существований, которые он вынужден вести. Так, например, в рассказе «Водяная тюрьма» герой признается: «Я чувствовал всегда, что та жизнь, которую я вел в этой гостинице...была лишь одним из многочисленных видов моего существования, проходившего одновременно в разных местах и в разных условиях - в воздухе и в воде, здесь и за границей...и я знал, что, живя и двигаясь там, я задеваю множество других существований — людей, животных и призраков» [5, с. 249].

Теософский ракурс Г. Газданов заявляет в романе «Вечер у Клэр» именем Бёме, вопрос только в наиболее созвучной корреляции эзотерического знания миру Г. Газданова, которому на наш взгляд ближе всего идеи «диссоциации» личности современного ему Г. Гурджиева. О плюралистичности сознания как «душевной болезни» говорят все герои-визионеры Г. Газданова В «Возвращении Будды» спиритуальный повествователь озабочен не только самоидентификацией, но и самой точкой 
сборки сознания: «чем я был связан с этими воображаемыми людьми, которых я никогда не выдумывал и которые появлялись с такой же неожиданностью, как тот, кто сорвался со скалы и в ком я умер не так давно» [6, с. 148]. Возникает вопрос, если он их «никогда не выдумывал», то кто их «воображает»? Это «невозможная» способность саморефлексии недавно умершего - транспозиция призрака, остраняющая в своей невиридиктивности реальность. Основная мысль Г. Гурджиева в том, что человек не знает самого себя; то, что он называет самосознанием - множество турбулентных псевдоя, которые образовались за счёт бесчисленных отождествлений с другими. Безымянный нарратор в «Возвращении Будды» так комментирует «мир, в котором одному из них суждено быть таким, а второму другим, может вдруг оказаться условным и призрачным, и тогда все опять неузнаваемо изменится. Другими словами, то, в чем проходило мое существование, было лишено для меня резко ограниченных и окончательных в каком-то смысле очертаний, в нем не было ничего постоянного, вещи и понятия, его составлявшие, могли менять форму и содержание, как непостижимые превращения бесконечного сна» [6, с. 145].

Отсутствие самосознания превращает человека в биологическую машину. В «Призраке Александра Вольфа» портрет боксёра: «У его соперника “круглые, крепкие плечи”» и толстые, «мускулистые ноги», и он напоминает «живую и неудержимую машину» [6, с. 41-42]. А также в описании тела героини контаминация биологического и механического делает Елену похожей на робота с «быстротой и точностью» движений и «ее стремительной походкой, мгновенностью и безошибочностью ее физических рефлексов» [6, с. 68], «тело с напряженными мускулами под блестящей кожей ее рук» [6, c. 58]. Механическим молохом выглядит в «Вечере у Клэр» муравейник, «втягивающий» тарантула. Агрегатность насилия манифестируется как универсальный закон природы. Тотальная автоматичность существования радикализована в философии Г. Гурджиева метафорой сна. Обычный европеец у него - «спящая машина». Лирический герой переживает катастрофу войны в вегетативной форме «спящего товарища» [5, с. 151], пассажира бронепоезда. Оптика разделённого внимания (актант/наблюдатель) фантазматично помещает его в утробу «загнанного зверя» [5, с. 146]. Сравнение бронепоезда со зверем как подчёркивает машинерность насилия, так и подключает метауровень восприятия насилия как зла из машины.

Пробуждение от сна достижимо через суровое самоостранение, взгляд на свою жизнь извне с позиции внешнего и нелицеприятного Наблюдателя. В прозе Г. Газданова проверка себя на прочность отличается от духовной кропотливой работы в наследии Г. Гурджиева. Для главного героя в первом романе писателя способ познать своё истинное Я - создание самому себе экстремального вызова, добровольный риск участия в военных действиях, который привёл к новым испытаниям вынужденной эмиграции. Солдат в народных представлениях символизирует особое знание. Наряду с мельником, кузнецом в карнавальных шествиях он ассоциируется с лиминальным миром между жизнью и смертью, то есть с миром призраков. Поэтому всё описание Парижа в «Вечере у Клэр» «в неверном свете фонарей». Призрачный диегезис заграницы свидетельствует о состоянии «трансгрессии», герой не преодолел демаркацию от смерти мира войны к нормальной жизни. Образ Клэр в перспективе последующих романов писателя оказывается проводником в «странный», потусторонний мир бессмысленно передвигающихся горничных, суетящихся старух, странного запаха навоза (инфернальный симптом) и др.

В отличие от Г. Гурджиева, Г. Газданов видит решение проблемы животной агрессивности человека и дремлющей в нём совести в контексте наследия культуры. Его феноменология насильственной смерти имеет интертекстуальную природу. М. Рубинс находит параллели текста Г. Газданова с современным ему романом Г. Гессе «Степной волк»: «Оба романа заканчиваются на драматической ноте - их герои убивают своих «двойников», обе ситуации крайне амбивалентны и наводят на мысль о символическом самоубийстве» [14]. Интертекстульная зона притяжения мотива убийства как «дихотомия между его человеческой и звериной природой или как борение духовного, рационального и культурного начала с иррациональным, инстинктивным, импульсивным» [14] коренится для Г. Газданова ещё в творчестве А. Пушкина. Нелепостью и бессмыслицей выглядит в романе «Евгений Онегин» «убийство друга», строки из которого взяты эпиграфом к «Вечер у Клэр». Наибольшая изоморфность в художественном осмыслении трансгрессии убийства обнаруживается с «Преступлением и наказанием» Ф. Достоевского, чтение которого было потрясением и нарушением табу для подростка Н. Соседова. Герой, который, по мнению матери, обычно дома ведёт себя прилично, разбивает дверцу книжного шкафа, чтобы иметь доступ к запретному плоду — «тому Достоевского». О. Юрье- 
ва пишет об особом статусе этого мотива: «Эйдология символа «книжного шкапа» определяется идеей Достоевского о воздействии литературы на формирование характера и сознания человека... Не менее «достоевским» является в русской литературе начала XX века эйдологический символ стены. Структура и форма стены сами по себе предрасполагают к символизации: непроницаемость, высота, непреодолимость» $[18$, с. 19]. Символ стены часто встречается и у Г. Газданова как в прозе, так и в публичных выступлениях: «Существующие в нас стены кажутся нам часто непреодолимым препятствием для общения с людьми» [3, с. 195]. Преодоление стен между людьми трактуется у него в ракурсе просвещения и поиска кросскультурных соответствий, хотя это и нелегко. Трансформный мир интеллектуала-нарратора в «Возвращении Будды», оказавшись в ловушке кошмара, натыкается на «глухую стену» перед совершением убийства [6, с. 155]. Газдановская «дивинология» [13, с. 70] в условиях «искусственного...небожественного» [5, с. 148] положения дел в исторической действительности становится «кротовой норой», в том понимании, которое придал этому Д. Фаулз, а именно «связь с иными областями, иными мирами» [18, с. 7]. Разбитая стеклянная дверь в домашнюю библиотеку из патриархального детства писателя в России, полного настоящей любви, стала началом постижения западных «вавилонских библиотек» (Х. Борхес). «Я шагал по длинной и узкой улице Babylone» [5, c. 39], пишет русскоязычный писатель-осетин, намекая на ограниченность и обреченность «нематериальной биологии» [5, с. 118] европейской цивилизации.

«Призрак Александра Вольфа» заканчивается убийством-самоубийством: «Я бежал как во сне по коридору...время заклубилось и исчезло, унося в этом непостижимо стремительном движении долгие годы моей жизни. С серого ковра, покрывавшего пол этой комнаты, на меня смотрели мертвые глаза Александра Вольфа» [6, с. 136]. Героев Г. Газданова сближает с Раскольниковым то, что убийство происходит в ирреальной безотчётности между сном и бодрствованием, а также идея суицидальной обратимости: «Я себя убил, а не старушонку». Ф. Достоевский в свою очередь опирается на ряд произведений Ф. Шиллера («О взаимосвязи животной природы человека с его духовной природой (1780), «Разбойники» (1781), «Преступник из-за потерянной чести» (1786). По справедливому замечанию Х.-Ю. Геригка о двух антропологических «парадигмах» Достоевского: «Как для Шиллера и Гофмана, для него человеческая сущность становится видна не в нормальном и не в примерном, но в из ряда вон выходящем, в искажениях, следовательно, в отклонениях от нормы» [7, с. 290]. Ф. Шиллер, а за ним и Ф. Достоевский показывают, как раскол биологического и духовного делает возможным убийство. Неконтролируемость человеком (сон-оцепенение) своей природы как автоматической машины смерти у этих авторов создаёт перетекаемость мотива. У Г. Газданова это нечто обратное «символической смерти» в инициации, своеобразная антиинициация. Вместо «новой жизни» солдат-убийца подвергается трансгрессии, он превращается в «живой труп», эйдолон, призрак, не осознавая этого в полной мере. Убийство предстаёт одновременно и аффективным (не исключая Раскольникова, которому «инстинкт помогал»), и опосредованно отчуждённо механистичным, и в кошмарном оглушении (у Г. Газданова от войны, у Ф. Шиллера и Ф. Достоевского от самой идеи преступления, у А. Пушкина имеет место нарциссический комплекс Онегина), а также в безвольной кратковременной парализации совести. При этом онейротопика становится приёмом фантастического. «Откровенно чудесное (ужасное, не-объяснимое, чужое) испытывает чувства и принуждает их признать существование ирреального, подчиниться силе невозможного» [11, с. 73]. Самое страшное, что произошло в «Пленнике» — это адинатон (impossibile), «ожившего» протеза пленного, показывая симультанность наших представлений о видимом мире и опасность поверхностного восприятия реальности: «Офицер не мог пошевельнуться; он молча стоял на снегу, опустив ненужный револьвер и чувствуя, что сейчас произойдет что-то страшное. Он дернул головой. Деревянный кулак пленного ударил его два раза по лицу; он упал ничком в снег и остался лежать неподвижно» [6, с. 702]. Действительным пленником оказывается здесь борющийся со сном офицер, который и проигрывает «дуэль».

Во всех упомянутых текстах игра между фактуальным и имагинативным, возможным и невозможным провоцирует перечитывание текста в неочевидной экспликации. Например, вполне возможно, что ситуация убийства и последующие действия в лихорадочной атмосфере «Преступления и наказания» были сновидением - интериоризацией, «реализмом в высшем смысле», подобно ирреализму г-на Голядкина в «Двойнике». И хотя у Ф. Достоевского это сон разума, а у Пушкина уступка условностям, в результате - абсурдность убийства, особенно подчёркнутая гибелью сестры старухи-процентщицы. И Г. Газданов, и Г. Гурджиев сознательную жизнь человека представляют 
как путь к новому уровню существования. Стремление человека к изменению и преодолению автоматизма бифуркационно принимает форму эволюции или деградации. Крайней формой трансгрессии предстаёт убийство, которое совершается в полной потере самосознания, в глубоком кошмарном сне вплоть до отождествления себя с орудием убийства. Говорящая фамилия «Раскольников» референирует героя в момент трансгрессии как человек-топор или, говоря тезаурусом Г Гурджиева, происходит «отождествление» героя с топором.

Насильственная смерть как абсурд войны у Г. Газданова доведена до предела с помощью мотива сна. Его ирреалистическая многозначность позволяет исследователям (Ю. Матвеева [12], Е. Асмолова [1], Е. Яблоков [20]) трактовать «Вечер у Клэр» в версиях сноподобия, а И. Сухих не без основания предположил, что экспозиционный отрезок вечера у Клэр в Париже лишь сон [17]. Можно выдвинуть версию, что в «Призраке Александра Вольфа» безымянный нарратор есть призрак, который не осознаёт этого, и тогда выстрел в конце романа, превращающегося в фантасмогорию, реплицируется в месть за собственную смерть. «Мне хотелось, чтобы на моей совести не было вашей смерти, и чтобы я не сделал вас убийцей в свою очередь. - И я тоже вспоминал об этом, — сказал я. — Я дорого дал бы за то, чтобы все эти годы не преследовал ваш призрак. - Как все условно! - сказал Вольф. - Вы были убеждены, что убили меня, я был уверен, что вы погибли по моей, в конце концов, вине <...>. Кто нам вернет это время и кто изменит вашу или мою судьбу?» [6, с. 109].

Е. Кузнецова пишет о Г. Газданове — об «особом типе его художественного мышления, в котором равнозначными и равновеликими оказываются и рациональное, и иррациональное начала» [10, c. 15]. Как интенсиональный сюжет сквозь «сетку» этого мира-конструкта просачивается и университетская книжность, и «языковые игры» модернизма, и русская классическая литература в синтетическом единстве. «Ничтожным призраком» называет пушкинская Татьяна Евгения Онегина. И если у А. Пушкина западное выглядит отчасти пародийно, то мир чужой культуры, куда фатально попадает эмигрант из России, сменяющий мир убийств гражданской войны, образует текучую неопределённость страшной ирреальности. Александр Вольф - романтический герой байронического типа, в русской традиции - это в большей степени Печорин М. Лермонтова. Е. Ахматова ассоциирует происхождение этого типа с Адольфом Б. Констана [2]. Мортальный персонаж - романтик Г. Газданова «лишний» не в социуме, а в жизни как феноменологической редукции. Он «по ту сторону любого отмщения», как концептуализирует «призрак» К Мейясу: «Настоящие призраки - это умершие, которые всегда будут противиться «переходу на тот свет» и упрямо избавляться от своего савана, дабы заявить живым наперекор фактам, что они всё еще принадлежат их числу. Их смерти не свидетельствуют ни о каком смысле и ничего не завершают» [13, с. 70]. Этимоном «при-зрака» является «зрак». Глаза - это портал между миром живых и мёртвых. В народной культуре глаза после смерти «выступают не как орган зрения, а как канал, отверстие, через которое покинувшая тело душа может вернуться назад» [21, с. 56]. Призрак - это обратная перспектива на текущую реальность из другого измерения. В художественной философии Г. Газданова он играет роль аналитической креатуры, нечто вроде мысленного эксперимента в формате романного персонажа, подобие «философского зомби». «Рассказы о призраках всегда нарушают рациональный мир яви, показывая, что его прочность и чёткость границ - иллюзия, они дают уверенному в себе и позитивистски настроенному читателю понять, что мир очевидных фактов и вещей на самом деле зыбок и представляет лишь поверхность жизни» [9, с. 58].

Трансгрессия убийства противоположна эффекту обретения самосознания, совести - по Г. Гурджиеву. В этот момент человек безвозвратно утрачивает человеческую душу, а его жертва становится призраком. На войне и после её окончания нет жертвы и убийцы, они амбивалентные призраки, неодушевлённые винтики «спящей машины» насилия. Так «защитник» (значение имени «Александр»), ставший призраком, стреляет в свою возлюбленную, а его противник случайно оказывается ее спасителем, хотя незадолго до этого во внутреннем монологе он же патологично романтизировал магнетизм убийства: «В этих нескольких секундах насильственного прекращения чьей-то жизни заключалась идея невероятного, почти нечеловеческого могущества... эту безличную притягательность убийства, которую так отдаленно и теоретически знал и я, и с которой началась история мира - в тот день, когда Каин убил своего брата и этой минутной властью убийства. Мне принадлежит эта власть, и я тоже могу стать ее жертвой, и если я испытывал ее притягательность, то все остальное, находящееся вне пределов этого представления, мне кажется призрачным, несущественным и неважным, и я не могу уже разделять того интереса ко множеству незначительных вещей, ко- 
торые составляют смысл жизни для миллионов людей. С той минуты, что я знаю это, мир для меня становится другим и я не могу жить, как те, остальные, у которых нет ни этой власти, ни этого понимания, ни этого сознания необыкновенной хрупкости всего, ни этого ледяного и постоянного соседства смерти» [6, с. 113-114]. Здесь противостояние людей в намерении убийства предстаёт не как аффект, но как маниакальная виктология. При этом трансгрессия как метамотивное явление, идущее от шиллеровского Вольфа и идеолога «права» на убийство Раскольникова, в безымянном нарраторе Г. Газданова приобретает форму шизоидного транса.

Можно рассматривать отмеченные здесь тексты как метароман призрачно-сновидческого Я. Безымянный повествователь в «Возвращении Будды» «привык давно в неотступности этого призрачного мира, который так неизменно следовал за мной» [6, с. 154]. Он вынужден применять превентивную меру в безвыходной ловушке войны или безлюдного уличного тупика, чтобы спасти свою биологическую жизнь, но убийство не спасает от мучительного существования. Катастрофу насилия в виде мировых войн проза Г. Газданова позиционирует как тотальность, втягивающую и время между войнами - посттравматический период эмиграции, в которой нет победителя. «Защита жизни» с оружием в руках оборачивается новым насилием и в конечном счёте - глобальным безумием «тяжёлой» от насилия «земли» в «Пленнике» или, другими словами, земли, обременённой насилием. Остранение реальности через магический кристалл онейротопа позволяет увидеть трагическое превращение действительности в иллюзию, а имплицидная метафора человека как «спящей машины» даёт новые подходы к пониманию природы насилия.

Резюмируя, следует подчеркнуть, что тема убийства, тесно связанная с творчеством А. Пушкина, Ф. Достоевского и Ф. Шиллера, у Г. Газданова оборачивается трансгрессией суицидального типа. С другой стороны, положительный модус этой темы воплощается в буддийской идее «перерождения» или её гурджиевском варианте, как пробуждение от сна иллюзорной реальности и метаморфоза биологической машины в истинное Я. В состоянии «сна наяву» человек - машина, управляемая внешними влияниями. Он ничего не может «делать». С ним всё случается. Чтобы «делать», необходимо «Быть», быть пробуждённым. Так в романе «Пробуждение» «средний француз» без пафоса, не рисуясь, помогает ближнему своему обрести здравый ум — и эта обыкновенность в перевёрнутом мире модернисткой эстетики выглядит как иносказание. Но это тоже обманчиво - инобытие есть, иносказания нет. Для пробуждённого героя добро - обычное дело.

В трилогии, ставшей пуантом действия «Призрака Александра Вольфа», подобно статьи Раскольникова о сверхчеловеке в «Преступлении и наказании», центральный рассказ — «Золотые рыбки». Две симметричные рыбки - символ буддизма, гармония эмпирического и потустороннего. Александр Вольф - «защитник» вечности, которая воплотилась в его писательском труде, убедительность которого признаётся всеми. Даже он не в состоянии преодолеть трансгрессию насилия, которую получил на фронте. Метамотив насильственной смерти - сквозной для большей части произведений Г. Газданова. Он объединяет писателя с гуманистической традицией, направленной на осознание и преодоление тёмных сторон природы человека, и всегда у него в страшной реальности есть лучик надежды: или «прекрасный сон о Клэр», или «золотые рыбки» буддизма.

\section{СПИСОК ИСТОЧНИКОВ И ЛИТЕРАТУРЫ}

1. Асмолова E. В. Мифологема «внутренней вселенной» героя в творчестве Газданова. В кн.: Гайто Газданов в контексте русской и западноевропейских культур. М.: ИМ Л И РАН, 2008.- 304 с.

2. Ахматова Е. В. "Адольф" Бенжамена Констана в творчестве Пушкина. 1936 (текст). feb-web.ru. Дата обращения 17 июля 2019.

3. Бабич И.Л. Гайто Газданов и масонская ложа «Северная звезда» (1932-1971 годы) // Новый исторический вестник. 2016. № 49(3), с. 184-199

4. Бернштам T. А. Молодежь в обрядовой жизни общины XIX-начала XX в.: половозрастной аспект традиционной культуры. Л.: Наука, 1988. 277 с.

5. Газданов, Г. Собрание сочинений: В 5 т. Т. 1.. М.: Эллис Лак, 2009. 880 с.

6 Газданов, Г. Собрание сочинений: В 5 т. Т. 3. М.: Эллис Лак, 2009. 736 с.

7. Геригк Х.-Ю. «Литературное мастерство Достоевского в развитии». СПб. Изд-во Пушкинского Дома, 2016.

4. $320 \mathrm{c}$.

8. Иванов E. E. Ирреализм в романе Г. Газданова «Вечер у Клэр» // ФИЛОLOGOS. 2019. 4 (43), с. $33-41$. 
9. Кизима М. Диалог романтизма и реализма в американской литературе рубежа XIX-XX веков: мистическое и фантастическое в творчестве Эдит Уортон. В кн.: Парадигмы переходности и образы фантастического мира в художественном пространстве XIX-XXI вв.: коллективная монография. Нижний Новгород: Изд-во ННГУ им. Н.И. Лобачевского, 2019, с. 463 с.

10. Кузнецова E. B. Тенденции в романной прозе Г. Газданова. В кн.: Теоретические и практические аспекты лингвистики, лингводидактики, литературоведения, культурологии, перевода и межкультурной коммуникации. Астрахань, Изд-во: ФГБОУ «Астраханский государственный университет", 2019, с. 15-18.

11. Лахманн Р. Л. Дискурсы фантастического. Перевод с немецкого. М.: Новое литературное обозрение, 2009. $384 \mathrm{c}$.

12. Матвеева Ю. «Превращение в любимое»: Художественное мышление Гайто Газданова. Екатеринбург: Изд-во Урал. ун-та, 2001. 100с.

13. Мейясу К. Дилемма призрака // Логос, 2 (92), 2013. С. 70-80.

14. Рубинс М. Русский Монпарнас. Парижская проза 1920-1930-х годов в контексте транснационального модернизма // ООО «Новое литературное обозрение», 2017 https: iknigi.net/avtor-mariya-rubins/146089-russkiymonparnas-parizhskaya-proza-19201930-h-godov-v-kontekste-transnacionalnogo-modernizma-mariya-rubins.html дата обращения 28. 01. 20.

15. Руднев В. П. Прочь от реальности: Исследования по философии текста. М.: «Аграф», 2000. 432 с.

16. Смирнова Е. Д. Возможные миры и понятие «картин мира» // Вопр. философии. 2017. № 1. С. 39-49.

17. Сухих И. Клэр, Машенька, ностальгия. Звезда. 2003. № 4. Цит. по: http://magazines.russ.rU/zvezda/2003/4/suh.html. Дата обращения: 26.04.2014.

18. Фаулз Д. Кротовые норы / Пер. с англ. И. Бессмертной, И. Тогоевой. М.: Махаон, 2002.

19. Юрьева О. Ю. Учение об идее Ф. М. Достоевского и эйдологический статус символики в русской литературе начала ХХ столетия // Казанская наука, 2019. № 3, с. 25-28.

20. Яблоков E. A. Железный путь к площади согласия («Железнодорожные» мотивы в романе «Вечер у Клэр» и в произведениях Булгакова). Газданов и мировая культура: Сб. научных статей. Калининград: ГП «КГТ», 2000, с. 148-174.

21. Ясинская М. В. Представления о глазах и зрении в языке и традиционной культуре славян. дис. ... к. филол. н.: Институт славяноведения РАН, М., 2016. 278 с.

Иванов Евгений Евгеньевич, аспирант кафедры филологии и методики, отделение гуманитарно-эстетического образования,

Иркутский государственный университет, ФГБОУ ВО «Иркутский государственный университет», 664003, Россия, Иркутск, ул. Карла Маркса, дом 1. e-mail: ayaom@list.ru

\section{E. E. Ivanov \\ METAMOTIVES OF POWERFUL DEATH IN PROSE OF GAYTO GAZDANOV}

DOI: 10.35634/2412-9534-2020-30-2-311-319

The article analyzes the role of the metamotive of violent death in the poetry poetry of Gazdanov (The Return of the Buddha, The Phantom of Alexander Wolf, The Prisoner). In this case, the motive for the murder is considered in connection with the motive of sleep as a single semantic complex, reflecting the transgression of going beyond the limits of present reality. The Oneirotop in these works not only defines the modes of the impossible (such as the elimination of reality through the narration of the ghost in "Return of the Buddha" or irrealism in "The Ghost of Alexander Wolf"), but also conveys the immanent author's strategy of "rebirth". In this article, the gazdanov hero's intention to gain selfhood is first described in terms of Gurdjieff's ideas ("man-sleeping machine", "pluralism of consciousness", etc.). Gazdanov's literary texts correlate with the provisions of his teaching on the moral transformation of personality. Using traditional methods of continuous sampling, motivational and typological analysis, specific features of the metamotive 
of violent death were revealed by G. Gazdanov in intertextual coverage. The Gazdanov hero is represented in the anthropological paradigm of F. Schiller-A. Pushkin-F. Dostoevsky, on the one hand, on the other hand, defines his place in the romantic series of "extra people" coming from Adolf Constant. The altered state of consciousness in the form of a fight against sleep, which is observed in all texts and allows us to talk about the metatextuality of the topic of murder in the writer's work, is separately noted. Through the prism of the meta-motive of violent death, a new approach is proposed to understanding G. Gazdanov's dominant discourse of mortality, which is presented as an intention to "awakening". The experience of transition in the context of the phantom and likeness of war and emigration totally eliminates historical reality and is assessed as anti-stabilization. At the same time, the unshakable faith of the lyrical hero in "rebirth" manifests vitalism, which turns out to be the paradoxical underside of mortality

Keywords: irrealism, oneirotope, transgression, "sleeping machine", the motive for the murder.

\section{REFERENCES}

1. Asmolova E. V. Mifologema «vnutrennej vselennoj» geroja v tvorchestve Gazdanova. V kn.: Gajto Gazdanov v kontekste russkoj i zapadnoevropejskih kul'tur. [Gaito Gazdanov in the context of Russian and Western European cultures] M.: IM L I RAN, 2008.- 304 s. (In Russian).

2. Ahmatova E. V. "Adol'f" Benzhamena Konstana v tvorchestve Pushkina. ["Adolph" by Benjamin Constan in the works of Pushkin] 1936 (tekst). feb-web.ru. Data obrashhenija 17 ijulja 2019. (In Russian).

3. Babich I.L. Gajto Gazdanov i masonskaja lozha «Severnaja zvezda» (1932-1971 gody) // Novyj istoricheskij vestnik. 2016. № 49(3). S. 184-199. (In Russian).

4. Bernshtam T. A. «Molodezh' v obrjadovoj zhizni obshhiny XIX-nachala XX v.: polovozrastnoj aspekt tradicionnoj kul'tury [Youth in the ritual life of the community of the 19th - early 20th centuries: the age and sex aspect of traditional culture] L.: Nauka, 1988. 277 s. (In Russian).

5. Gazdanov, G. Sobranie sochinenij: V 5 t. T. 1. [Collected Works: In 5 vol. T. 1.] M.: Jellis Lak, 880 s. (In Russian).

6 Gazdanov, G. Sobranie sochinenij: V 5 t. T. 3. [Collected Works: In 5 vol. T. 3.] M.: Jellis Lak, 2009. - 736 s. (In Russian).

7. Gerigk H.-Ju. «Literaturnoe masterstvo Dostoevskogo v razvitii». [Dostoevsky's literary mastery in development. From "Notes from the House of the Dead" to the "Brothers Karamazov"] SPb. Izd-vo Pushkinskogo Doma, 2016. T. 4. 320 s. (In Russian.)

8. Ivanov E. E. Irrealizm v romane G. Gazdanova «Vecher u Kljer»// FILOLOGOS. 2019. 4 (43). S. 33-41. (In Russian).

9. Kizima M. Dialog romantizma i realizma v amerikanskoj literature rubezha XIX-XX vekov: misticheskoe i fantasticheskoe $\mathrm{v}$ tvorchestve Jedit Uorton. V kn.: Paradigmy perehodnosti i obrazy fantasticheskogo mira $\mathrm{v}$ hudozhestvennom prostranstve XIX-HHI vv.: kollektivnaja monografija. [Transition paradigms and images of the fantasy world in the art space of the XIX - XXI centuries] Nizhnij Novgorod: Izd-vo NNGU im. N.I. Lobachevskogo, 2019. s. 463 s. (In Russian).

10. Kuznecova E. V. Tendencii v romannoj proze G. Gazdanova. V kn.: Teoreticheskie i prakticheskie aspekty lingvistiki, lingvodidaktiki, literaturovedenija, kul'turologii, perevoda i mezhkul'turnoj kommunikacii. [Theoretical and practical aspects of linguistics, linguodidactics, literary criticism, cultural studies, translation and intercultural communication] Astrahan', Izd-vo: FGBOU «Astrahanskij gosudarstvennyj universitet", 2019. S. 15-18. (In Russian).

11. Lahmann R. L Diskursy fantasticheskogo. Perevod s nemeckogo. [Discourses of the Fantastic] M.: Novoe literaturnoe obozrenie, 2009. 384 s. (In Russian).

12. Matveeva $J u$. «Prevrashhenie v ljubimoe»: Hudozhestvennoe myshlenie Gajto Gazdanova. ["Turning Into a Beloved": Gaito Gazdanov's Artistic Thinking] Ekaterinburg: Izd-vo Ural. un-ta, 2001. — 100s. (In Russian).

13. Mejjasu K. Dilemma prizraka // Logos, 2 (92), 2013 S. 70-80. (In Russian).

14. Rubins M. Russkij Monparnas. Parizhskaja proza 1920-1930-h godov v kontekste transnacional'nogo modernizma // OOO «Novoe literaturnoe obozrenie», 2017 [Russian Montparnasse. Parisian prose of the 1920-1930s in the context of transnational modernism] https: iknigi.net/avtor-mariya-rubins/146089-russkiy-monparnas-parizhskayaproza-19201930-h-godov-v-kontekste-transnacionalnogo-modernizma-mariya-rubins.html data obrashhenija 28.01. 20. (In Russian).

15. Rudnev V. P. Proch' ot real'nosti: Issledovanija po filosofii teksta [Away from Reality: Text Philosophy Studies] M.: «Agraf», 2000. 432 s. (In Russian).

16. Smirnova E. D. Vozmozhnye miry i ponjatie «kartin mira»// Vopr. filosofii. 2017. № 1 S. 39-49. (In Russian).

17. Suhih I. Kljer, Mashen'ka, nostal'gija. Zvezda. 2003. № 4. Cit. po: http://magazines.russ.rU/zvezda/2003/4/suh.html. Data obrashhenija: 26.04.2014. (In Russian).

18. Faulz D. Krotovye nory / Per. s angl. I. Bessmertnoj, I. Togoevoj [Mole burrows] M.: Mahaon, 2002. (In Russian). 
19 Jur'eva O. Ји. Uchenie ob idee F. M. Dostoevskogo i jejdologicheskij status simvoliki v russkoj literature nachala HH stoletija // Kazanskaja nauka, 2019. № 3. S. 25-28. (In Russian).

20. Jablokov E. A. Zheleznyj put' k ploshhadi soglasija («Zheleznodorozhnye» motivy v romane «Vecher u Kljer» i v proizvedenijah Bulgakova). Gazdanov i mirovaja kul'tura: Sbornik nauchnyh statej [Gazdanov and world culture] Kaliningrad: GP «KGT», 2000. - S. 148-174. (In Russian).

21. Jasinskaja M. V. Predstavlenija o glazah i zrenii v jazyke i tradicionnoj kul'ture slavjan. dis. ... k. filol. n.: Institut slavjanovedenija RAN [Representations of the eyes and eyesight in the language and traditional culture of the Slavs] M.: 2016.-278 s. (In Russian).

Received: 20.07.2019.

Ivanov E.E., Graduate Student,

Department of Philology and Methodology,

Department of Humanities and Aesthetic Education,

Irkutsk State University,

664003, Russia, Irkutsk, Karl Marx st., 1.

e-mail: ayaom@list.ru

ORCID- 0000-0002-9937-4357, ResearcherID A-2667-2019 